Article

\title{
Evaluating Common-Mode Voltage Based Trade-Offs in Differential-Ended and Single-Supplied Signal Conditioning Amplifiers
}

\author{
Marko Petkovsek *(D) and Peter Zajec (D)
}

Faculty of Electrical Engineering, University of Ljubljana, Trzaska 25, SI-1000 Ljubljana, Slovenia; peter.zajec@fe.uni-lj.si

* Correspondence: marko.petkovsek@fe.uni-lj.si; Tel.: +386-14768862

check for updates

Citation: Petkovsek, M.; Zajec, P. Evaluating Common-Mode Voltage Based Trade-Offs in DifferentialEnded and Single-Supplied Signal Conditioning Amplifiers. Electronics 2021, 10, 1982. https://doi.org/ 10.3390/electronics10161982

Academic Editor: Gaetano Palumbo

Received: 21 July 2021

Accepted: 15 August 2021

Published: 17 August 2021

Publisher's Note: MDPI stays neutral with regard to jurisdictional claims in published maps and institutional affiliations.

Copyright: (c) 2021 by the authors. Licensee MDPI, Basel, Switzerland. This article is an open access article distributed under the terms and conditions of the Creative Commons Attribution (CC BY) license (https:/ / creativecommons.org/licenses/by/ $4.0 /)$.

\begin{abstract}
This paper focuses on a differential voltage measurement in low-voltage automotive devices whose subunits are separated with a low-side safety switch. In contrast to conventional applications with high-side switches, a common-mode voltage (CMV) with negative polarity exists at the input of the signal conditioning circuitry. To overcome the shortage of dedicated integrated circuits capable of withstanding negative CMV, the paper investigates single- and two-stage differential circuits with single-supplied operational amplifiers to find a cost-optimized counterpart. In addition, the proposed procedure tunes the circuit parameters in such a manner to obtain the largest possible full-scale range at the output. Though, such optimization results in very uncommon values for gain and reference voltages. This issue is additionally evaluated for reference voltages that are either cost-effective or more easily accessible to increase the circuit feasibility. Since the impact of resistances on circuits' behaviour could be diminished to a great extent using high-precision and matched pair resistors, the sensitivity analysis was investigated only for a reference voltage change. Furthermore, a reversed termination of measured voltages results in a simplified reference voltage selection without hindering circuits' performance, proven by simulation and experimental results.
\end{abstract}

Keywords: voltage measurement; common-mode voltage; operational amplifier; differential-ended signal conditioning; low-side switch; high-power device

\section{Introduction}

Hardly ever all subunits of an electronic device in a modern vehicle share the same reference [1,2], i.e., ground potential. This situation calls for the implementation of signal conditioning circuits which merge all subunits into one functional part. Thus, their properties, including gain, frequency bandwidth [3] and common-mode specifications, should match the subunits' input and output requirements.

The ground difference depends on a relative position between a load and a main switch that disconnects the main supply from the load. We differentiate two types of applications, i.e., with a low-side and a high-side switch [4,5]. Whereas the control of the simplest loads is generally obtained through the high-side switch, more complex loads (DC/DC, DC/AC converters) incorporate either high- or low-side safety switches to disconnect the device from the power source in case of emergency [6]. A control scheme of a modern converter [7-9] contains numerous signal conditioning circuits [10,11], generally interfaced with a supervising microcontroller [12,13], to acquire currents and voltages and to supervise its operation. This case is addressed and clarified on a simplified converter scheme (Figure 1) that consists of two subunits whose negative terminals are connected through a low-side safety switch. The latter offers superior functionality in terms of increased safety over the high-side switch topology - not so much in a normal operation mode, but above all in case of a severe malfunction or even misuse of the device. For instance, in case of an unintentional (outer) connection of $u_{H P+}$ and $u_{M G}$ terminals only 
the low-side switch can prevent the power flow towards the load. For a reliable operation of the high-power device, the designated voltages $\left(u_{\text {meas }}=\left\{u_{a g}, u_{H P}\right\}\right)$ from an auxiliary subunit must be acquired in all operation modes (start-up, failure, regular operation). During these modes, the safety switch can take two discrete states (open, closed).

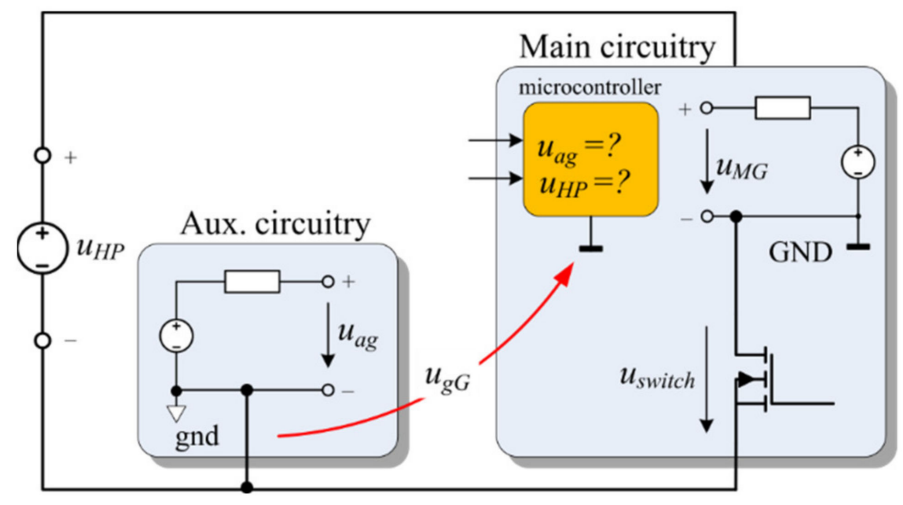

Figure 1. Simplified representation of an automotive device with a low-side safety switch.

The magnitude of the common-mode voltage (CMV) at the input of the signal conditioning circuit may, as a result, vary extensively and can change with a high slew rate during low-side switch transitions. However, neither of both voltage phenomena restricts the design of the conditioning circuit more than the fact that CMV has a negative polarity. Besides, rare usage of low-side switch topologies causes a shortage of suitable and costeffective components for signal conditioning. It is worth mentioning that the highlighted CMV issue is, in general, much easier to handle with dedicated ICs, featuring a build-in isolation barrier (i.e., optic couplers) like in [14]. In automotive applications not exceeding $60 \mathrm{~V}$, galvanic isolation is not mandatory. Thus, using the insulating couplers to transfer logic signals between both stages would not be cost-effective.

To overcome the shortage of dedicated ICs, we decided to analyse and evaluate some custom-built circuits with operational amplifiers. OP amps with rail-to-rail input and output (RRIO) specifications, whose CMV range not only equals but can also go beyond the supply range, were supposed. Though, the range extends only for some tens of millivolts, i.e., up to a $0.5 \mathrm{~V}$ increase beyond each supply rail is acceptable in case of a low voltage OP amp ON NCV5230 [15] or an automotive TI TLV9001 [16].

The paper is organized as follows: In Section 2, two single-supplied differential conditioning circuits that are tolerant to negative CMV are investigated. For both circuits, a procedure for circuit parameter determination is proposed to obtain the largest possible full-scale range at the output for a given input voltage and CMV range. Section 3 provides key simulation results for both circuits, followed by a possible approach for further circuit parameter optimization focusing on the reference voltages used. Based on simulation results, one signal conditioning circuit was selected and implemented in the laboratory prototype of an advanced DC/DC converter for the automotive industry. Finally, in Section 4, experimental results for voltage measurement in the DC/DC converter prototype are given.

\section{Common-Mode Voltage Restrictions in Single-Supplied Differential Circuits}

During the design of the signal conditioning circuit for systems like in Figure 1, three voltage ranges (hereafter designated with capital $U$ ) must be considered: (1) full-scale measuring voltage range $\left(U_{F S, \text { meas }}\right)$ that yields to $(2)$ full-scale output voltage range $\left(U_{F S, \text { out }}\right)$ and, (3) common-mode voltage range $\left(U_{C M}\right)$ that is applied between both subunits. Consequently, diverse circuit topologies impose different CMV at the input of the chosen IC, which in turn emphasizes the choice of an appropriate topology for the signal conditioning circuit. 
In Figure 1, the measured voltages $\left(u_{a g}, u_{H P}\right)$ are referenced against the "gnd" point; in contrast, the measuring circuitry is terminated at the "GND" reference. The voltage difference $u_{g G}$ between both sub-units ground potentials is not constant. It varies according to the safety switch status from some $\mathrm{mV}$, when the switch is closed, up to the magnitude of $u_{H P}$ in its open state. Since in the latter situation, the level of measuring voltage can be even three decades smaller than the $u_{g G}$, its effect would not be adequately rejected at the output of single-ended amplifier circuits.

In such voltage circumstances, measuring circuitry with differential-ended topology at the input front-end is a standard solution. Figure 2 shows its basic implementation with a single supplied OP amp. A general approach representing the voltage circumstances at the input terminals is applied. The measured voltage $\left(u_{\text {meas }}\right)$ is substituted with a difference between input voltages $\left(u_{i{ }^{+}}, u_{i n-}\right)$, both being referenced against GND. In general, they can be decomposed into a differential $u_{D M}$

$$
u_{D M}=u_{i n+}-u_{i n-}=u_{\text {meas }},
$$

and a common-mode voltage $u_{C M}$

$$
u_{C M}=\frac{u_{i n+}+u_{i n-}}{2},
$$

which excites both terminals with the same intensity. To reject its impact on the output voltage $\left(u_{\text {out }}\right)$

$$
u_{\text {out }}=\frac{R_{2}}{R_{1}+R_{2}}\left(1+\frac{R_{4}}{R_{3}}\right) u_{\text {in }+}-\frac{R_{4}}{R_{3}} u_{\text {in- }},
$$

the resistances $R_{3}=R_{1}$ and $R_{4}=R_{2}$ must be paired, resulting in

$$
u_{\text {out }}=\frac{R_{2}}{R_{1}}\left(u_{\text {in }+}-u_{\text {in- }}\right)=\frac{R_{2}}{R_{1}} u_{\text {meas }} \text {, }
$$

where a ratio $R_{2} / R_{1}$ defines a gain $G$.

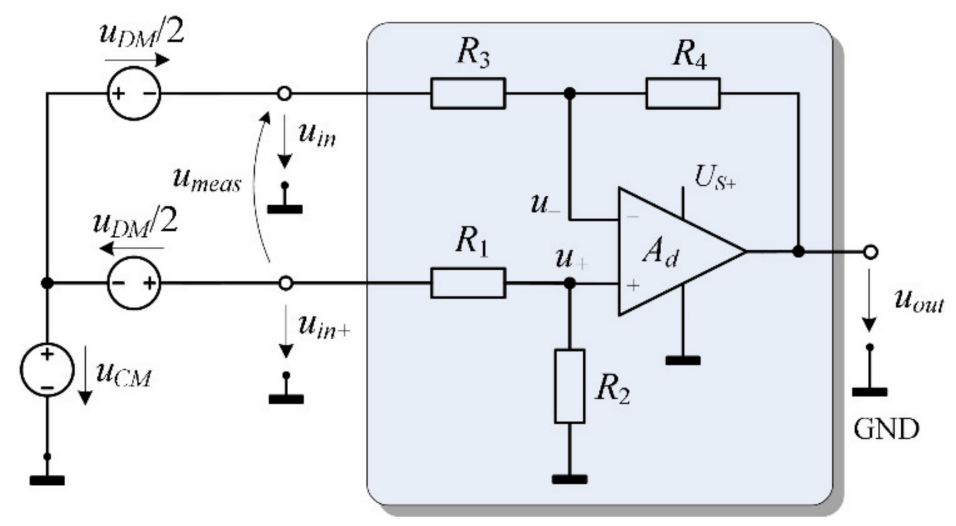

Figure 2. OP amp configured as a difference amplifier.

By comparing the voltage notations in Figures 1 and 2, the derived CMV at the input of the difference amplifier $\left(u_{C M}\right)$ reveals its dependency on the switch state (i.e., $\left.u_{g G}\right)$

$$
u_{C M}=u_{g G}+\frac{u_{m e a s}}{2} .
$$

In (5), an infinitive rejection of CMV, provided by perfect resistance matching and an ideal OP, is assumed. In contrast, the real OPs exhibit a finite capacity given by CMRR to 
reject CMV $\left(u_{C M, O P}\right)$ being present directly at the inputs of the operational amplifier. Its correlation to the system-related CMV $\left(u_{C M}\right)$ can be derived straightforwardly

$$
u_{C M, O P}=u_{+}=\frac{R_{2}}{R_{1}+R_{2}}\left(u_{g G}+u_{\text {meas }}\right)=\frac{R_{2}}{R_{1}+R_{2}}\left(u_{C M}+\frac{u_{\text {meas }}}{2}\right)
$$

by assuming that the differential voltage $\left(u_{d}=u_{+}-u_{-}\right)$tends to zero, i.e., by an infinite differential gain $\left(A_{d}\right)$. To attain the assigned OP operation, the voltage at the input (6) and output (4) must be within its input and output (IO) boundaries. According to (4), the polarity of the measured voltage is preserved at the output side. Thus, input terminals reversal, yielding in $u_{\text {meas }}<0$, is not allowed under any circumstance since a negative output voltage in a single supplied OP amp is not attainable. In reality, the voltage boundaries of individual OP families differ substantially. For further simplification, the IO voltage boundaries match the positive $\left(U_{\mathrm{S}_{+}}\right)$and negative $(0 \mathrm{~V})$ rail supply voltage. Thus, an ideal RRIO OP amp is assumed.

As a result, the selected gain in (4) should agree with the preferred full-scale range of $u_{\text {meas }}$, not to violate the positive supply rail. On the other hand, fulfilling the input restrictions relating to CMV (6) is often marginalized in practice, especially in singlesupplied OP circuits. Usually, this occurs because most users merely focus on CMV rejection, i.e., CMRR capabilities $[17,18]$. The other cause might be that they do not differentiate between the system-related CMV from one present on OP inputs. Therefore, if resistances $\left(R_{1}\right.$ and $\left.R_{2}\right)$ are selected merely to boost gain in (4), the CMV present at the inputs of the OP could violate (6) limits. The OP operation is particularly jeopardized when the $u_{g G}$ polarity is negative, and its magnitude prevails over $u_{\text {meas }}(6)$, driving the $u_{C M, O P}$ towards the negative rail of the supply. In our case, the described situation occurs by a rule whenever the safety switch is open.

\subsection{Biased Differential Circuits}

An extra reference voltage $u_{R E F}$ (Figure 3 ) resolves an inadequate tolerance to negative $\mathrm{CMV}$ revealed in (6). It biases the noninverting input of the $\mathrm{OP}$ and consequently increases its CMV away from the negative supply rail.

$$
u_{C M, O P}=\frac{R_{2}}{R_{1}+R_{2}} u_{i n+}+\frac{R_{1}}{R_{1}+R_{2}} u_{R E F} .
$$

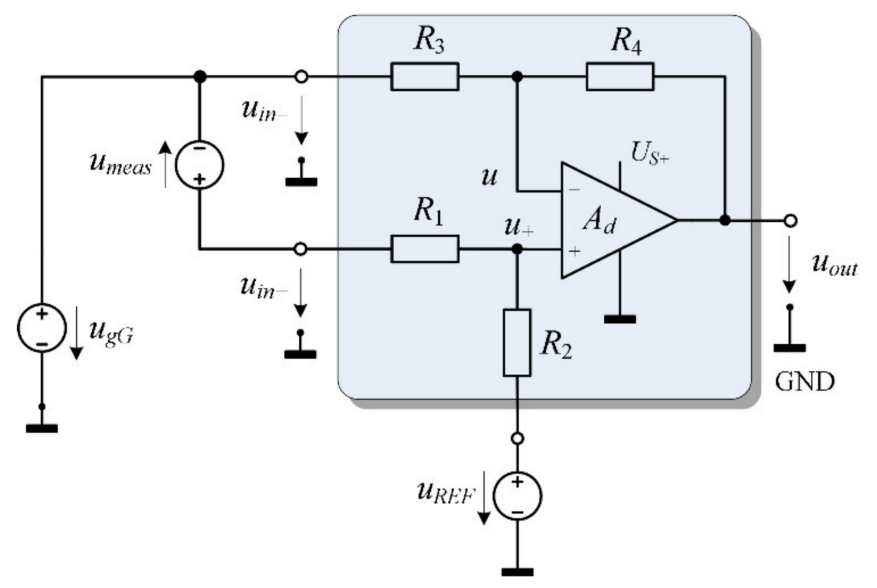

Figure 3. OP amp configured as a biased difference amplifier.

Considering $R_{3}=R_{1}$ and $R_{4}=R_{2}$, the applied voltage at circuit's input converts to $u_{\text {out }}$

$$
u_{\text {out }}=\frac{R_{2}}{R_{1}}\left(u_{\text {in+ }}-u_{\text {in- }}\right)+u_{R E F}=\frac{R_{2}}{R_{1}} u_{\text {meas }}+u_{R E F} .
$$


Referring to (8) it is found that even in the worst-case scenario $\left(u_{\text {meas }}=0 \mathrm{~V}\right.$, $\left.u_{g G}=u_{g G, \max }\right)$, the CMV restriction at negative supply rail can be easily fulfilled such to choose

$$
u_{R E F}^{*}=-u_{g G, \max } \cdot \frac{R_{2}}{R_{1}} .
$$

On the other side, the selected reference (9) confines the available output full-scale voltage down to

$$
U_{F S, o u t}=U_{S+}-u_{R E F}^{*}
$$

and by inserting (9) into (8), consequently the gain as well

$$
\left(\frac{R_{2}}{R_{1}}\right)^{*}=\frac{U_{S+}}{U_{F S, \text { meas }}-u_{g G, \text { max }}}=G^{*}
$$

The (11) is derived in such a way to prevent $u_{\text {out }}$ escaping beyond the positive rail $\left(U_{S_{+}}\right)$even in the worst-case scenario $\left(U_{F S, \text { meas }}, u_{g G}=u_{g G, \text { max }}\right)$.

\subsection{Two-Stage Difference Amplifiers}

To increase $U_{F S, \text { out }}$ across the entire rail to rail range of the OP $\left(U_{F S, \text { out }}=U_{S+}\right)$, a second amplifier stage is required (Figure 4), transforming the output voltage of the first stage (8) into

$$
u_{\text {out }}=\left(\frac{R_{22}}{R_{21}}\left(\frac{R_{2}}{R_{1}} u_{\text {meas }}+u_{R E F}\right)-u_{R E F}\right)=\frac{R_{2}}{R_{1}} \frac{R_{22}}{R_{12}} u_{\text {meas }} .
$$

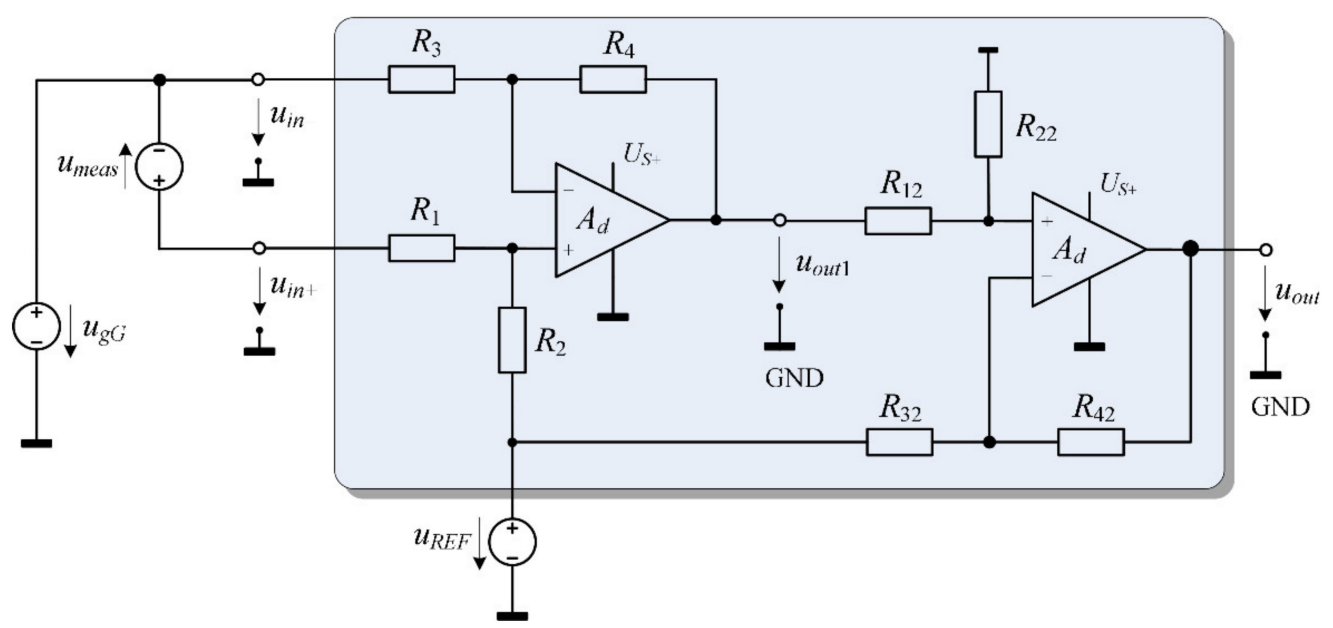

Figure 4. OP amp configured as a biased two-stage amplifier.

In (12), the second stage gain $R_{22} / R_{12}$ follows the same logic as in the first stage if setting $R_{12}=R_{32}$ and $R_{22}=R_{42}$. A complemented stage does not change $u_{C M, O P}$ at the input of the first stage, whereas the second is inherently exposed solely to the positive $u_{C M, O P}$. For further evaluation, however, we have identified only the differential amplifier shown in Figure 3 since the feature of the second stage in Figure 4 (12) is more easily implemented within the MCU.

A similar topology as in Figure 4 is implemented in a programmable gain difference amplifier from [19], featuring very high CMRR, however offering only a limited gain adjustment and-in case of using it with a single supply only, also a limited tolerance to negative CMV.

\subsection{Two-Stage Difference Amplifier Based on Instrumentation Amplifier Topology}

In general, in environments where a measurement path is exposed to electromagnetic emissions [20-23] and severe CMV issues, instrumentation amplifiers are implemented as 
a rule $[24,25]$. They exhibit excellent CMRR features [26,27], however, they tolerate rather modest CMV and their gains are higher than 1 [28], limiting their use in the presented case as shown later on.

In the following, an alternative two-stage amplifier is offered to emphasise the CMV issue. Namely, since the $u_{C M, O P}(7)$ for circuit from Figure 3 varies correspondingly with the applied CMV, the input crossover phenomena related to OP input topology [29] could distort the output voltage. The alternative amplifier, seen in Figure 5 and adopted from [30], page 418 , has inherently a two-stage topology. Its output voltage can be expressed as

$$
u_{\text {out }}=\frac{R_{2}}{R_{1}} \frac{R_{F}}{R_{G 1}} u_{\text {in }+}-\frac{R_{F}}{R_{G 2}} u_{\text {in- }}-\left(1+\frac{R_{2}}{R_{1}}\right) \frac{R_{F}}{R_{G 1}} u_{R E F 1}+\frac{R_{F}+R_{G 1} \mathrm{II} R_{G 2}}{R_{G 1} I I R_{G 2}} u_{R E F 2}
$$

where a sign "II" denotes a parallel connection of resistances. To attain high CMRR (i.e., rejecting $u_{g G}$ ), the resistance quotients in front of $u_{i n+}$ and $u_{i n}$ in (13) must be equal. Subsequently, all four resistors should comply with

$$
\frac{R_{2}}{R_{1}}=\frac{R_{\mathrm{G} 1}}{R_{\mathrm{G} 2}} .
$$

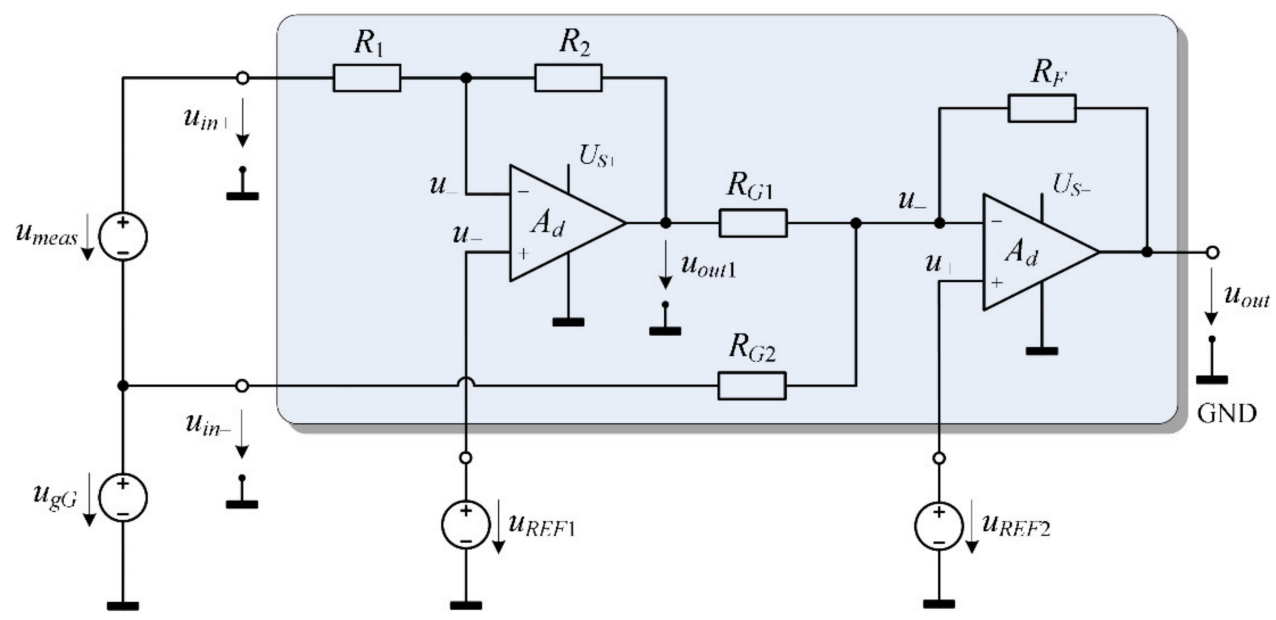

Figure 5. A schematic of a two-stage difference amplifier.

The relations $R_{1}=R_{G 2}$ and $R_{2}=R_{G 1}$ should also be met, to assure the impedance symmetry at the front-side of the amplifier. Thus, the (13) simplifies to

$$
u_{\text {out }}=\frac{R_{F}}{R_{G 2}} u_{\text {meas }}-\frac{R_{F}}{R_{G 1} \mathrm{II} R_{G 2}} u_{R E F 1}+\frac{R_{F}+R_{G 1} \mathrm{II} R_{G 2}}{R_{G 1} \mathrm{II} R_{G 2}} u_{R E F 2} .
$$

The CMV at both OPs can be deduced straightforwardly

$$
\begin{aligned}
& u_{+, 1}=u_{C M, O P 1}=u_{R E F 1}, \\
& u_{+, 2}=u_{C M, O P 2}=u_{R E F 2} .
\end{aligned}
$$

Thus, the reference voltages must be positive and their magnitude inside the supply rail-to-rail levels to meet input OP restrictions. Since the same argument applies to $u_{\text {out }}$ in (15), their magnitudes cannot be arbitrarily chosen. Namely, according to (15), the CMV applied (i.e., $u_{g G}$ ) affect neither of the $u_{C M, O P}(16)$ nor (17), but it does affect the $u_{\text {int }}=u_{\text {meas }}+u_{g G}$, and the output voltage of the first OP consequently

$$
u_{o u t 1}=-\frac{R_{2}}{R_{1}} u_{i n+}+\left(1+\frac{R_{2}}{R_{1}}\right) u_{R E F 1} .
$$


Based on (18), two conditions should be met to comply with IO restrictions: (i) the output voltage $u_{\text {out } 1}$ must not sink below zero even when the $u_{\text {meas }}$ matches its full-scale value $\left(U_{F S, \text { meas }}\right)$ and $u_{g G}=0 \mathrm{~V}$, and (ii) output voltage $u_{\text {out } 1}$ must be less or equal to positive supply rail $\left(U_{S+}\right)$ for the worst-case situation $\left(u_{\text {meas }}=0 \mathrm{~V}, u_{g G}=u_{g G, \max }\right)$. After combining both conditions, the first stage gain

$$
\left(\frac{R_{2}}{R_{1}}\right)^{*}=\frac{U_{S+}}{U_{F S, \text { meas }}-u_{g G, \max }}=G_{1}^{*} .
$$

and the reference voltage $u_{R E F 1}^{*}$ derive

$$
u_{R E F 1}^{*}=\frac{R_{2}}{R_{1}+R_{2}} U_{F S, \text { meas }} .
$$

Substituting $u_{R E F 1}$ in (18) with (20) proves that $u_{\text {out } 1}$ does not violate negative supply rail when worst-case combination $\left(u_{g G}=0 \mathrm{~V}, u_{\text {meas }}=u_{\text {meas, } \text { max }}=U_{F S, \text { meas }}\right)$ is present.

If $u_{\text {out }}=0 \mathrm{~V}$ is to be achieved at $u_{\text {meas }}=0 \mathrm{~V}$, that is to transform (15) into

$$
u_{\text {out }}=\frac{R_{F}}{R_{G 2}} u_{\text {meas }},
$$

the reference voltage $u_{R E F 2}$ should fulfil the derived equilibrium

$$
\frac{R_{F}}{R_{G 1} \mathrm{II} R_{G 2}} u_{R E F 1}=\frac{R_{F}+R_{G 1} \mathrm{II} R_{G 2}}{R_{G 1} \mathrm{II} R_{G 2}} u_{R E F 2} .
$$

By rearranging (22), it is found that the preferred variables of the second stage relate firmly

$$
u_{R E F 2}^{*}=\frac{R_{F}^{*}}{R_{F}^{*}+R_{G 1} \mathrm{II} R_{G 2}} u_{R E F 1}^{*} .
$$

However, since the value of $R_{1}=R_{G 2}$ is already determined, the $R_{F}$ cannot be randomly selected. It should also fulfil (21) deducing that voltages match their maximum allowed value, summarising into

$$
R_{F}^{*}=\frac{U_{S+}}{U_{F S, \text { meas }}} R_{1} .
$$

In contrast to derived equations, a trivial selection $\left(u_{R E F 1}=u_{R E F 2}=0\right)$ that comply with (15) but fails to maintain (18) above negative supply rail at $u_{g G}=0 \mathrm{~V}$ was rejected from the beginning.

\section{Simulation-Based Performance Review}

This section's findings and discussion are grounded exclusively on results obtained from simulations performed in LTspice and transferred into Excel for graphical representation. An ideal OP amp, with $\mathrm{IO}$ restriction matching the positive $\left(U_{S_{+}}=3.3 \mathrm{~V}\right)$ and negative $(0 \mathrm{~V})$ rail supply voltage, was assumed. For elementary assessment in a steady-state condition, such simulation is adequate to identify the trade-offs of the considered circuits. Dynamic and frequency features of the signal conditioning circuits were thus put in the second plan.

Up to this point, we have established that proposed amplifier configurations, shown in Figures 3 and 5, tolerate negative CMV. However, their features, including the achieved full-scale range, parameter sensitivity, reference voltage feasibility and others are still to be judged.

For that purpose, two measured voltages with significantly different full-scale ranges $\left(U_{F S, a g}=3.3 \mathrm{~V}, U_{F S, H P}=60 \mathrm{~V}\right)$, denoted as blue bars in Figure 6, were applied to the input, in addition to the CMV ranging from $0 \mathrm{~V}$ up to $-60 \mathrm{~V}$. Following the procedure described in Section 2, we calculated circuits' setpoints (Table 1) for specific voltage ranges, such that 
$U_{F S, \text { out }}$ preferably occupies the entire rail-to-rail supply voltage range (denoted as a grey bar in Figure 6).

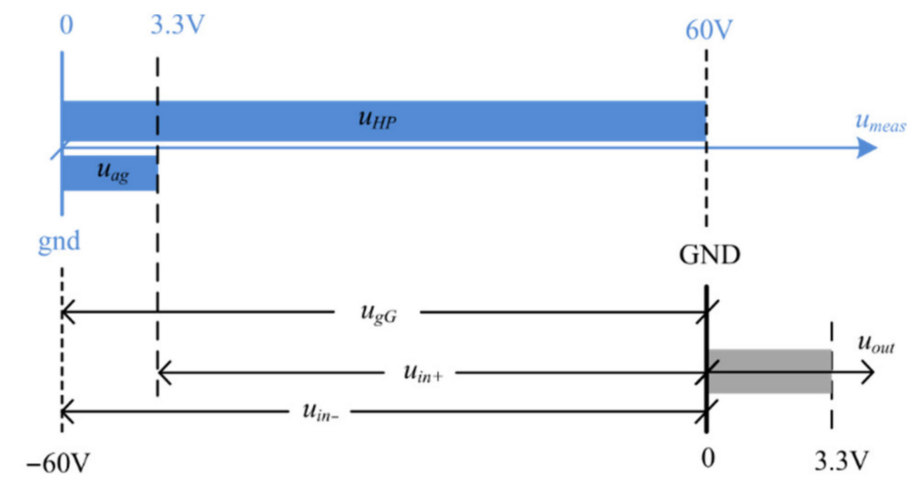

Figure 6. Designation of measured voltages in respect to gnd (in blue) and output voltage referenced to GND (in grey) (not in scale).

Table 1. Comparison between single- and two-stage difference amplifiers' setpoints.

\begin{tabular}{cccccccc}
\hline & \multicolumn{2}{c}{$\begin{array}{c}\text { Single-Stage } \\
\text { Difference Amplifier }\end{array}$} & \multicolumn{4}{c}{$\begin{array}{c}\text { Two-Stage } \\
\text { Difference Amplifier }\end{array}$} \\
\hline Voltage Range & $\boldsymbol{u}_{\boldsymbol{R} E \boldsymbol{F}}^{*}$ & $\boldsymbol{G}^{*}=\frac{\boldsymbol{R}_{\mathbf{2}}}{\boldsymbol{R}_{\mathbf{1}}}$ & $\boldsymbol{u}_{\boldsymbol{R} E \boldsymbol{F} \mathbf{1}}^{*}$ & $\boldsymbol{u}_{\boldsymbol{R} E \boldsymbol{2} \mathbf{2}}^{*}$ & $\frac{\boldsymbol{R}_{\mathbf{2}}}{\boldsymbol{R}_{\mathbf{1}}}$ & $\frac{\boldsymbol{R}_{F}}{\boldsymbol{R}_{G 1}}$ & $\frac{\boldsymbol{R}_{F}}{\boldsymbol{R}_{G 2}}$ \\
\hline$U_{F S, a g}=3.3 \mathrm{~V}$ & $3.128 \mathrm{~V}$ & 0.0521 & $0.1635 \mathrm{~V}$ & 0.1558 & 0.0521 & 19.185 & 1.0 \\
$U_{F S, H P}=60 \mathrm{~V}$ & $1.65 \mathrm{~V}$ & 0.0275 & $1.6058 \mathrm{~V}$ & 1.0802 & 0.0275 & 2.0 & 0.055 \\
\hline
\end{tabular}

Initially, the DC analysis was performed by sweeping the input voltages across the predefined full-scale range. Despite the CMV has the exact magnitude, Figure 7 reveals that the achieved output voltage in single- and two-stage amplifiers differs significantly. At $u_{\text {meas }[\mathrm{p.u}]}=1$, the input voltage is in all three cases amplified to $3.3 \mathrm{~V}$. Contrary, at the bottom margin $u_{\text {meas }[\mathrm{p.u}]}=0$, we got $3.128 \mathrm{~V}$ and $1.65 \mathrm{~V}$ for amplifying the $u_{a g}$ and $u_{H P}$ in the single-stage amplifier, respectively. At the same margin, the voltage in two-stage circuit is amplified to $0 \mathrm{~V}$. The revealed full-scale readings are consequently consistent with calculated ones in Table 2. Both input voltages are given in per unit scale, with the base corresponding to their maximum values.

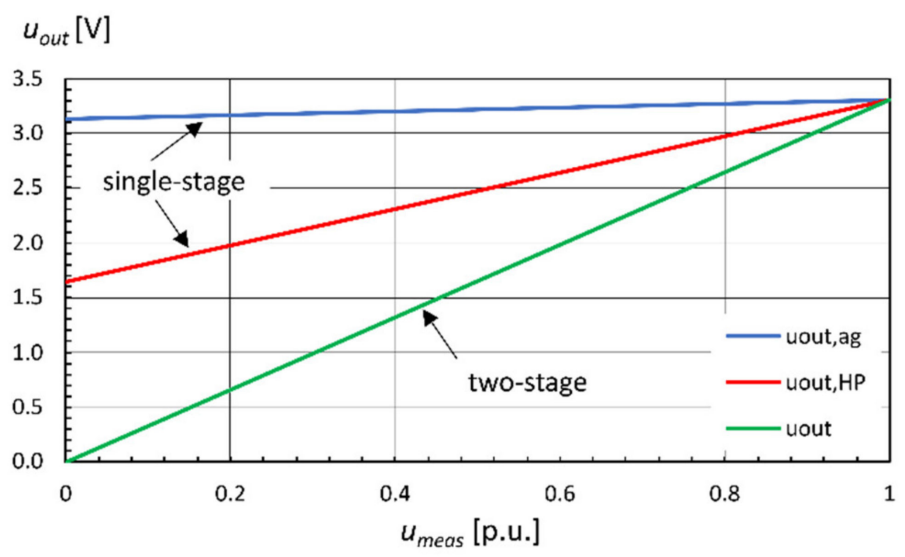

Figure 7. Input-to-output correlation for two measured voltages and amplifier topologies. 
Table 2. Comparison between calculated $U_{F S, \text { out }}$ for corresponding single- and two-stage amplifiers' setpoints.

\begin{tabular}{cccc}
\hline & $\begin{array}{c}\text { Single-Stage } \\
\text { Voltage Range }\end{array}$ & \multicolumn{2}{c}{$\begin{array}{c}\text { Two-Stage } \\
\text { Difference Amplifier }\end{array}$} \\
\cline { 2 - 4 } & $\boldsymbol{U}_{\boldsymbol{F S}, \text { out }}$ & $\boldsymbol{U}_{\boldsymbol{F S}, \text { out } \mathbf{1}}$ & $\boldsymbol{U}_{\boldsymbol{F S}, \text { out }}$ \\
\hline$U_{F S, a g}=3.3 \mathrm{~V}$ & $0.172 \mathrm{~V}$ & $0.172 \mathrm{~V}$ & $3.3 \mathrm{~V}$ \\
$U_{F S, H P}=60 \mathrm{~V}$ & $1.65 \mathrm{~V}$ & $1.65 \mathrm{~V}$ & $3.3 \mathrm{~V}$ \\
\hline
\end{tabular}

In the two-stage amplifier, the output voltage occupies the entire available range $(3.3 \mathrm{~V})$, irrespective of neither the CMV nor the full-scale range of the input voltage. In the single-stage amplifier, it is conversely limited into a smaller full-scale range. To make matters even worse, the range narrows as the input voltage range decreases; evident at $U_{F S, a g}=3.3 \mathrm{~V}$ where the output range is reduced to $0.172 \mathrm{~V}$. The latest also applies to the first OP $\left(U_{F S, \text { out } 1}\right)$ in the two-stage amplifier. In fact, the first stage must have the same attenuation (Table 1) as the single-stage amplifier does, irrespective of constant CMV presence at the OP inputs. Subsequently, the DC analysis was performed by sweeping the CMV across its predefined full-scale range. It was conducted on both circuits providing that the input voltages have been maintained on their margin values. Its purpose was to identify any conceptual flaw made in Section 2, primarily focusing on CMV $\left(u_{C M, O P}\right)$ violation. The results are summarized in Figures 8-10.

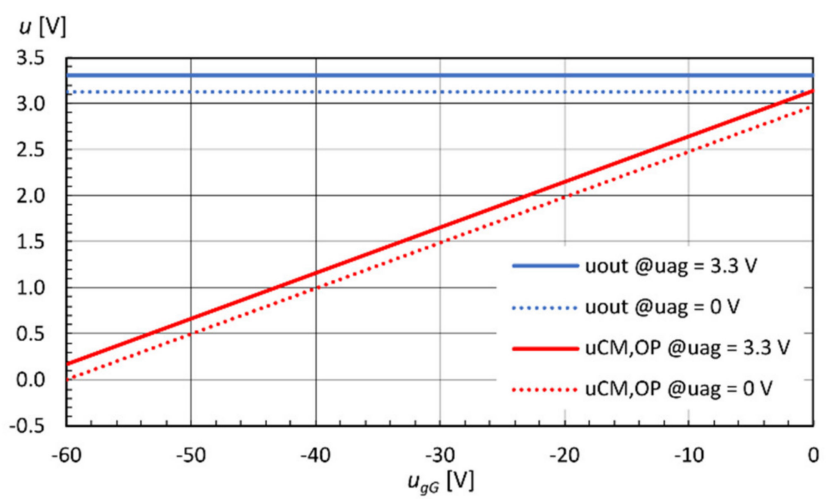

(a)

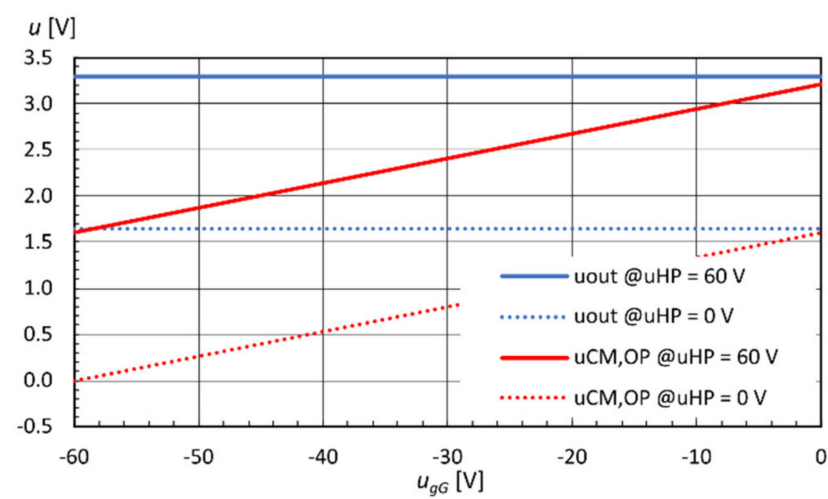

(b)

Figure 8. Single-stage circuit output $u_{\text {out }}$ and $u_{C M, O P}$ vs. $u_{g G}$ for limit input values for measurement of: (a) $u_{a g} ;(\mathbf{b}) u_{H P}$.

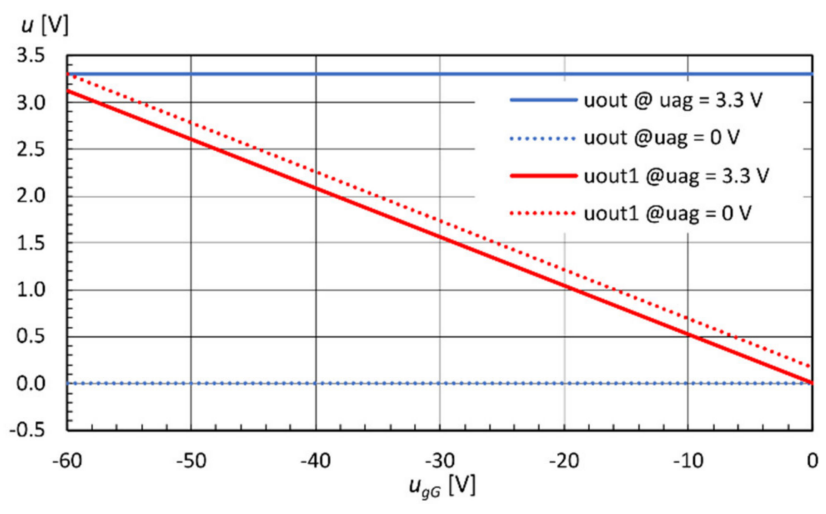

(a)

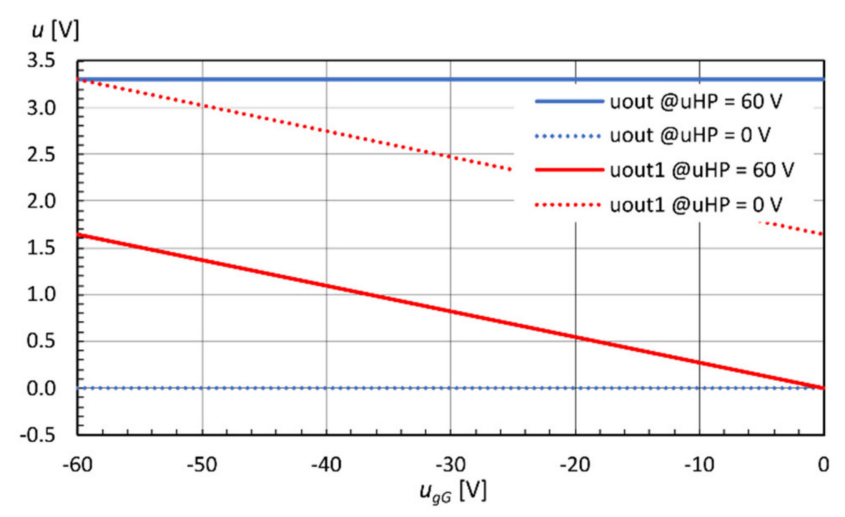

(b)

Figure 9. Two-stage circuit outputs $\left(u_{o u t}\right.$ and $\left.u_{o u t 1}\right)$ for limit input values vs. $u_{g G}$ for measurement of: (a) $u_{a g} ;$ (b) $u_{H P}$. 


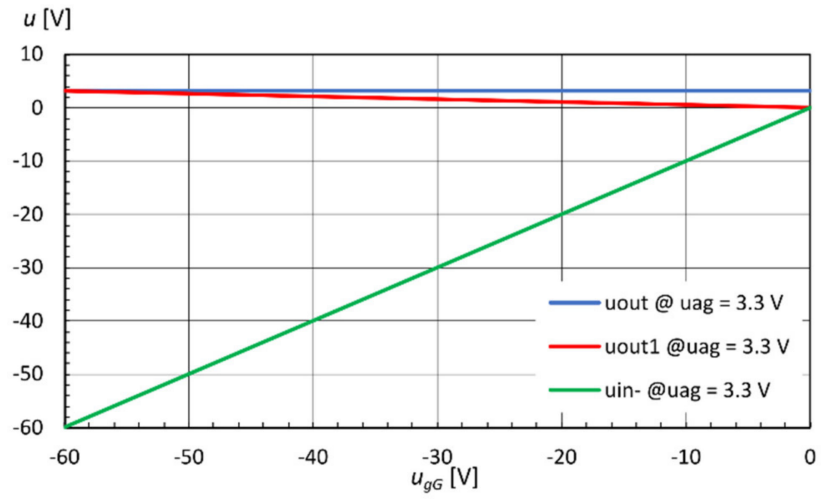

(a)

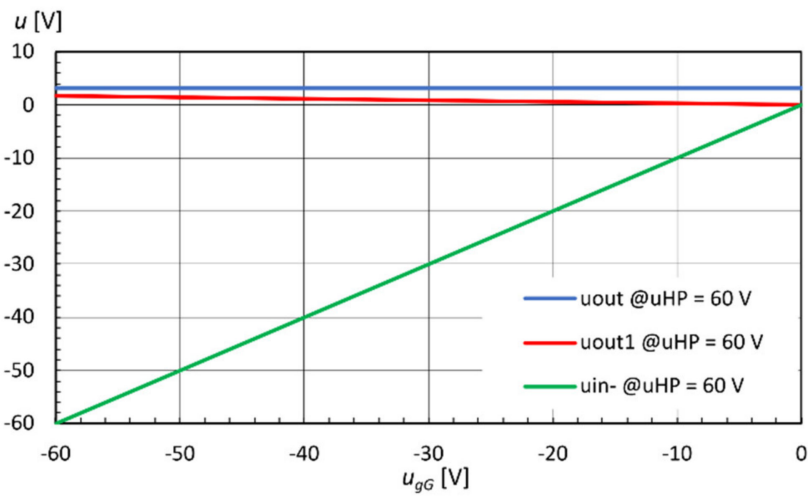

(b)

Figure 10. Two-stage circuit output $u_{o u t}$ and voltages at the second stage inputs vs. $u_{g G}$ for: (a) $u_{a g}=3.3 \mathrm{~V} ;(\mathbf{b}) u_{H P}=60 \mathrm{~V}$.

As can be seen, a stable voltage is identified at the output of the single-stage (Figure 8) and two-stage amplifier (Figure 9), regardless of the $u_{g G}$ variation. During its change, both figures demonstrate that the full-scale of each indicated voltage remains constant. Furthermore, the single-stage amplifier's features do not depend on $u_{C M, O P}$ fluctuations as long as they remain within the supply margins (Figure 8). The same is valid in the two-stage variant (Figure 9$)$, where the varying output voltage $\left(u_{\text {out } 1}\right)$ is fed to the second OP. Inherently to the circuit in Figure 5, this change has no impact on CMV on the OP inputs, although the circuit terminals are subjected to large negative $\mathrm{CMV}$, as emphasized in Figure 10. We want to recap this comparison referring back to Figure 7. It demonstrates a significantly smaller full-scale range for low input voltage $u_{a g}$, yet its measuring sensitivity $S$ is roughly twofold compared to $u_{H P}$.

$$
\frac{U_{F S, \text { out }}}{U_{F S, \text { meas }}}=\mathrm{S}
$$

\subsection{Parameter Sensitivity Analysis}

In general, during the circuit implementation, the discrepancy between calculated circuit parameters acquired from the proposed design procedure and those implemented regularly happens. The circuit parameters also deviate from their nominal values during the lifetime of a product. These deviations, which relate to production process tolerances, ageing mechanism, working environment temperature and other impacts, are usually neglected since they are small. However, in contrast to matched resistors, the voltage reference components exhibit a more significant deviation from their nominal specifications, particularly in terms of a temperature change [31,32]. Consequently, in the following analysis, we evaluated merely the impact of the reference voltages change while keeping the resistor values constant. We can justify this decision in two ways. First, the temperature coefficients of voltage reference components compared to those of matched pair resistors are higher-thus, a more significant effect was predicted. Furthermore, the pretty uncommon values displayed in Table 2 raised questions about reference voltage implementation, as well. Namely, although the shunt or series voltage references (such as TI LM4140 series [33]) are commercially available in the sub $1 \mathrm{~V}$ range [34-38] in conjunction with a survey in [39], their nominal values still differ substantially from requested. An auxiliary circuit, such as a voltage divider combined with an OP amp-based voltage follower, can resolve this situation. Though, at the cost of simplicity and cost-effectiveness.

Referring to a single-stage output voltage (8), any change of reference voltage $\Delta u_{R E F}$ causes the proportional change $\Delta u_{\text {out }}$ at the output

$$
\Delta u_{o u t}=\frac{\partial u_{o u t}}{\partial u_{R E F}} \cdot \Delta u_{R E F}=\Delta u_{R E F} .
$$


In the same way, the two-stage output voltage (15) is evaluated concerning only the change of the second stage's reference voltage (the explanation is provided in the following subsection).

$$
\Delta u_{o u t}=\frac{\partial u_{o u t}}{\partial u_{R E F 2}} \cdot \Delta u_{R E F 2}=\frac{R_{F}+R_{G 1} \mathrm{II} R_{G 2}}{R_{G 1} \mathrm{II} R_{G 2}} \cdot \Delta u_{R E F 2}=a \cdot \Delta u_{R E F 2}
$$

where $a$ represents the resistor's ratio. Introducing a percentage change of the reference $\left(u_{R E F}\right)$ and the output voltage

$$
\begin{aligned}
\Delta u_{R E F} \% & =\frac{\Delta u_{R E F}}{u_{R E F}} \cdot 100 \% \\
\Delta u_{\text {out } \%} & =\frac{\Delta u_{\text {out }}}{u_{\text {out }}} \cdot 100 \%,
\end{aligned}
$$

then using (26) and (27) for single-stage and two-stage circuits, respectively, the final relations follow

$$
\begin{gathered}
\Delta u_{\text {out } \%}=\frac{u_{R E F}}{u_{\text {out }}} \cdot \Delta u_{R E F \%} \\
\Delta u_{\text {out } \%}=a \cdot \frac{u_{R E F 2}}{u_{\text {out }}} \cdot \Delta u_{R E F 2 \%} .
\end{gathered}
$$

According to (30) and (31), any voltage reference deviation causes a proportional one in output voltage. Since its magnitude increases with an output voltage reduction, it could severely compromise the measurement accuracy, as illustrated in Figure 11, where a $1 \%$ reference voltage change is supposed, based on data from $[29,30]$. When $u_{a g}$ is amplified by single-stage circuit, the output error (30) is much larger (Figure 11a) compared to $u_{H P}$ measurement. Remember that particular reference values $\left(u_{R E F}=3.128 \mathrm{~V}\right.$ and $u_{\text {REF }}=1.65 \mathrm{~V}$ ) define the minimum output value.

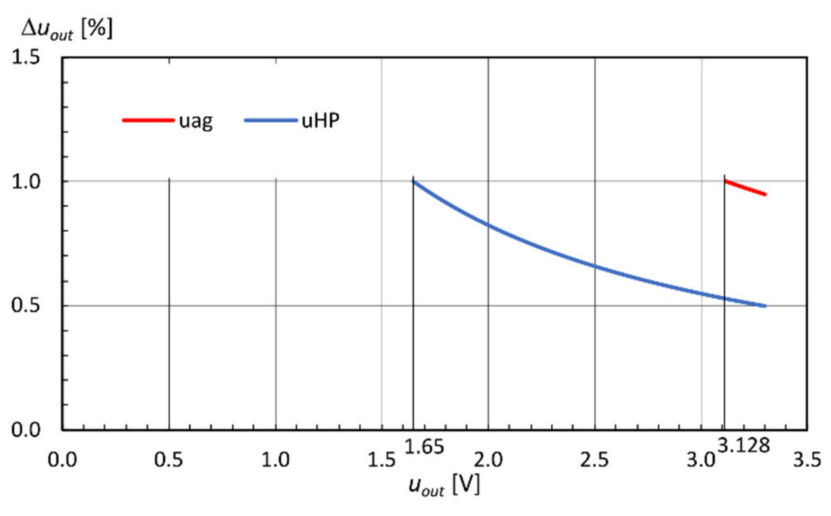

(a)

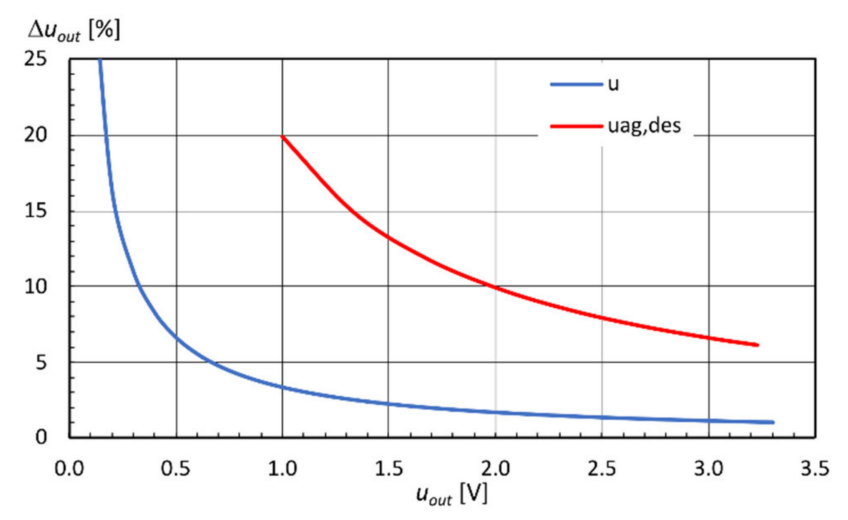

(b)

Figure 11. Percentage change of $u_{\text {out }}$ due to a $1 \%$ change in the reference voltage vs. the output voltage: (a) single-stage circuit; (b) two-stage circuit.

In two-stage circuit, the output error also depends on the resistance ratio $a$, as defined in (31). Since the ratio emerges already in general analysis, i.e., in (15) and (22) defining the calculated reference voltages (Table 1), thus it turns out that the ratio is identical regardless of the input voltage range. As a result, the voltage error (blue line in (Figure 11b), is identical for both measured voltages. This non-intuitive statement is valid as (1) in each case measured full-scale ranges are translated into identical rail-to-rail output voltage range, and (2) since the percentage change is expressed according to output voltage $u_{\text {out }}$.

In contrast, if we decide to replace the reference voltages, calculated from the proposed procedure with cost-effective and/or accessible on the market, the term $\left(a \cdot u_{R E F 2}\right)$ contrasts 
for individual voltage measurements. To illustrate this, suppose that the designated (labelled with des) references $\left(u_{R E F 1}=u_{R E F 2}=1 \mathrm{~V}\right)$ were applied instead of the calculated given in Table 1. The resistor values corresponding to $u_{a g}$ (Table 1) were recalculated to sustain the permissible input and output voltage change for both OP amps resulting in $R_{2} / R_{1}=0.039, R_{F} / R_{G 1}=17.419$ and $R_{F} / R_{G 2}=0.675$, correspondingly. Under these circumstances, the impact of a $1 \%$ reference voltage change is substantially higher (red line in Figure 11b; for selected references valid only above $1 \mathrm{~V}$ ) compared to the error for proposed reference voltages (blue line). This, in general, depreciates the use of "randomly" selected reference voltages. Despite the modification, the circuit reaches the positive rail at the output at the same maximum measured voltage $\left(u_{a g}=3.3 \mathrm{~V}\right)$, as evident in Figure 12 . On the other hand, when $u_{a g}$ is $0 \mathrm{~V}$, the output voltage equals the reference voltage value of $1 \mathrm{~V}$. Consequently, the output range $U_{F S \text {, out }}$ becomes smaller than the one displayed in Figure $9 \mathrm{a}$, obtained as a result of the proposed procedure.

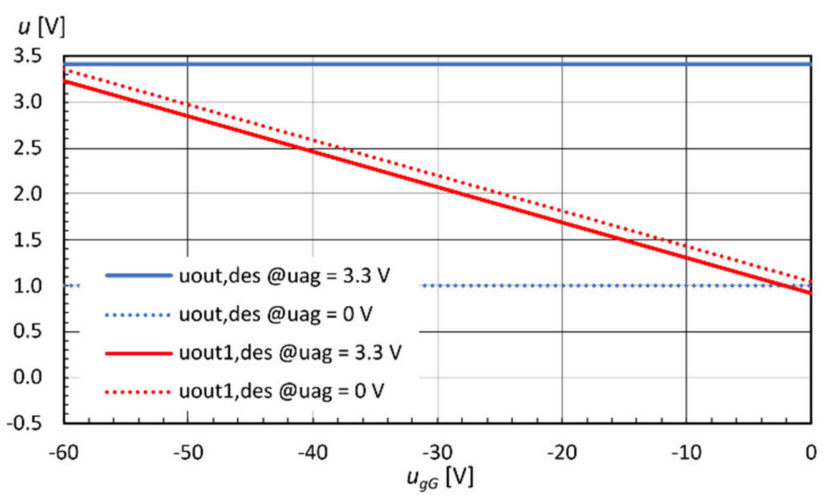

Figure 12. OP amp output $u_{o u t}$ vs. $u_{g G}$ for the measurement of $u_{a g}$ and designated reference voltages.

If the output range $U_{F S, \text { out }}$ is not of a primary design concern, both references can be chosen to fit the market offer considering the aforementioned drawbacks and OP amps IO specification.

\subsection{Evaluating the Impacts of the Reversed Terminal Connection}

The proposed procedure for parameter selection assumed the polarity of the measured voltage, as depicted in Figure 1, where the positive terminal (labelled+) is connected to the $u_{\text {in }}$ terminal of the measurement circuit and negative (-) to $u_{i n}$. However, considering the (7) strictly from the mathematical point of view, a similar operation of the circuit (Figure 3) is achieved with the reversed terminal connection, thus by applying negative voltage. To preserve the proper operation, the reference voltages $u_{R E F}$ must be changed. In a singlestage circuit, $u_{R E F}$ must, following (8) and (12), match positive supply rail $U_{S_{+}}$, irrespective of the measured voltage (i.e., $u_{a g}$ or $u_{H P}$ ). In contrast, $u_{R E F 1}$ must be changed to zero for the two-stage circuit while maintaining the same $u_{R E F 2}$ values as before. The result of such a change for both analysed circuits is for the measurement of $u_{a g}$ visible in Figure 13 and for the $u_{H P}$ in Figure 14. For both circuits and the measured voltage $u_{\text {meas }}=0 \mathrm{~V}$, the output voltage equals $u_{\text {out }}=U_{S_{+}}$. In contrast, for the maximum measured voltage, the output is at the value initially defined with the $u_{R E F}$ for a single-stage circuit $(3.128 \mathrm{~V}$ and $1.65 \mathrm{~V}$, respectively), whereas for the two-stage circuit, the output is zero. Since the reversed voltage connection imposes the voltage reference $u_{R E F 1}=0 \mathrm{~V}$, the output voltage error (15) can only depend on $u_{R E F 2}$, as defined (31). 


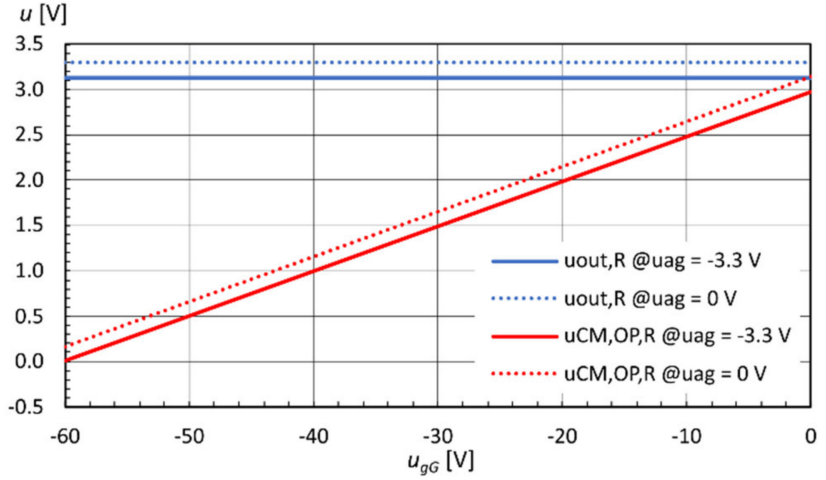

(a)

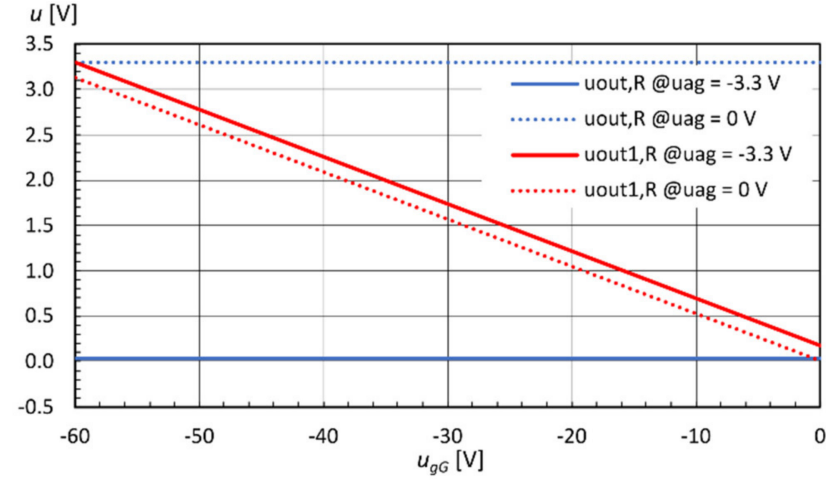

(b)

Figure 13. Characteristic voltages vs. $u_{g G}$ for the reversed $u_{a g}$ connection: (a) single-stage circuit; (b) two-stage circuit.

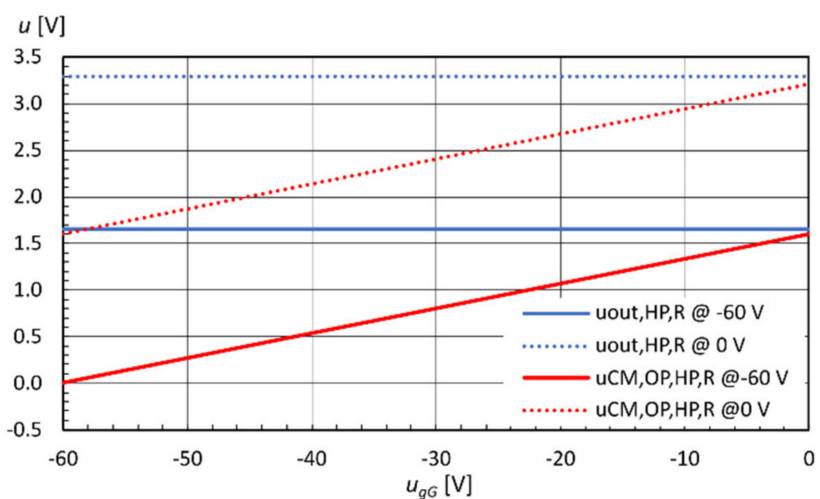

(a)

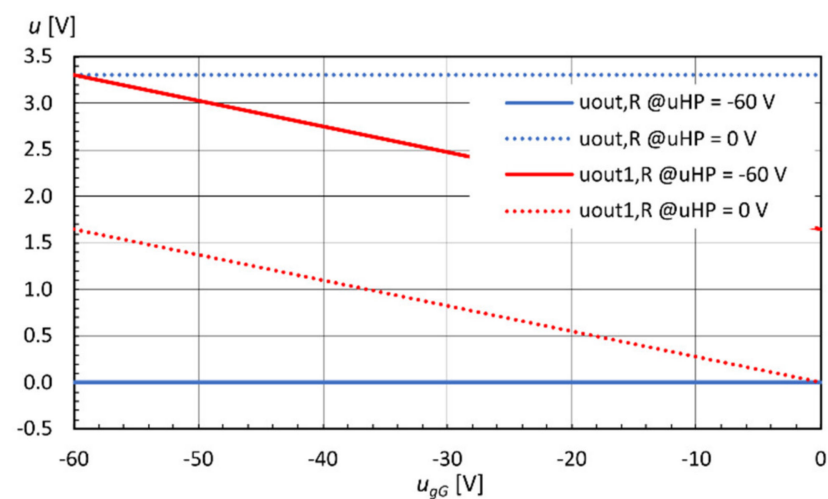

(b)

Figure 14. Characteristic voltages vs. $u_{g G}$ for the reversed $u_{H P}$ connection: (a) single-stage circuit; (b) two-stage circuit.

\section{Experimental Results}

A set of voltage measurements was performed on a laboratory prototype of an advanced $3.7 \mathrm{~kW}$ DC/DC converter (Figure 15), designed for the automotive industry to validate the proposed calculation procedure. Its topology is not essential for the subject and is adequately represented with the simplified scheme from Figure 1, with slight distinction regarding the safety switch topology. Namely, as seen in Figure 15, a back-to-back switch is implemented, where each set is composed of three N-channel MOSFET transistors. They can disconnect the DC/DC converter from the high-power supply $\left(U_{H P}=60 \mathrm{~V}\right.$ in Figure 1$)$ during normal operation if so required (stand-by mode), but above all, in case of failure or misuse of the device. $U_{H P}$ directly supplies the power stage and the control stage with peripheral conditioning circuits. Their purpose is to measure different voltages in an auxiliary circuitry. Since the safety switch separates both parts of the converter, the conditioning circuits are subjected to a negative CMV when the switch is disconnected.

The simulation results for two analysed signal conditioning circuits that can handle the negative CMV did not provide any strategic guidance or superiority favouring a specific circuit, so we opted to implement the simpler scheme from Figure 3.

Circuit parameters were selected following the proposed procedure and are given in Table 1 . The selection of resistance values, however, is not entirely arbitrary. Namely, since a voltage drop on $R_{1}$ (and $R_{3}=R_{1}$; Figure 3 ) could assume values as high as the power supply $u_{H P}(60 \mathrm{~V})$ or the $u_{g G}$, the $R_{1}$ value must be selected first. Furthermore, not only the preferred power rating of the elements to be used (i.e., $0.125 \mathrm{~W}$ ) but also a possible change of resistances due to self-heating needs to be considered and then followed by $R_{2}$ and $R_{4}$ (being equal to $R_{2}$ ) calculation. Their voltage drop is within the OP amp supply voltage and therefore excessing the resistor power rating is not an issue here. In the prototype, the 
value of $R_{1}=100 \mathrm{k} \Omega$ was selected for all cases, following with the calculation of $R_{2}$ for individual voltages based on data from Table 1 (all resistances used have a $0.5 \%$ tolerance).

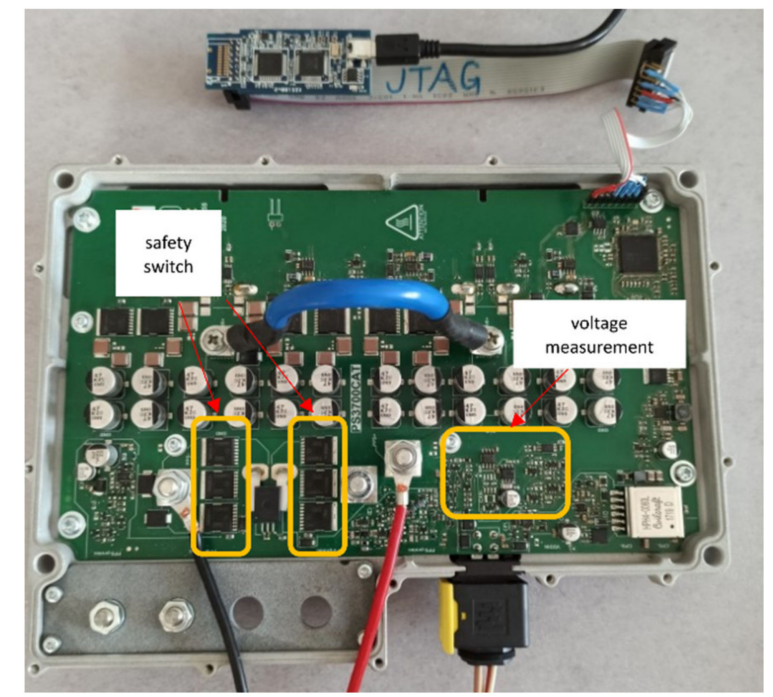

Figure 15. DC/DC converter prototype fitted with single-stage conditioning circuits.

In Figure 16, experimental results for voltage error (labelled deltaU) on the full-scale range of measured input voltages from $0 \mathrm{~V}$ to $U_{F S, a g}=3.3 \mathrm{~V}$ and $0 \mathrm{~V}$ to $U_{F S, H P}=60 \mathrm{~V}$ are displayed for original (labelled $u_{a g}$ and $\left.u_{H P}\right)$ and reversed polarity labelled $\left(u_{a g, R}\right.$ and $\left.u_{H P, R}\right)$ for $u_{g G}=0 \mathrm{~V}$. Next, both circuits were exposed to a changing negative CMV $\left(u_{g G}\right)$ from $0 \mathrm{~V}$ to $-60 \mathrm{~V}$, while preserving the measured voltages at their full-scale values of $U_{F S, a g}=3.3 \mathrm{~V}$ and $U_{F S, H P}=60 \mathrm{~V}$. As expected from Figure 8, the circuit output voltage should remain constant (i.e., at $3.3 \mathrm{~V}$ ) irrespective of the applied negative $\mathrm{CMV}$, however, this is not entirely true as seen from Figure 17. Otherwise, if the difference amplifier circuit is not well balanced (i.e., $R_{1} \neq R_{3}$ and /or $R_{2} \neq R_{4}$ ), we could expect a significant discrepancy compared to balanced (ideal) values. For comparison, Figure 17 also shows the calculated worst-case voltage error margin vs. imposed negative CMV for resistances variation of $\pm 0.5 \%$ (labelled R $0.5 \%$ limit).

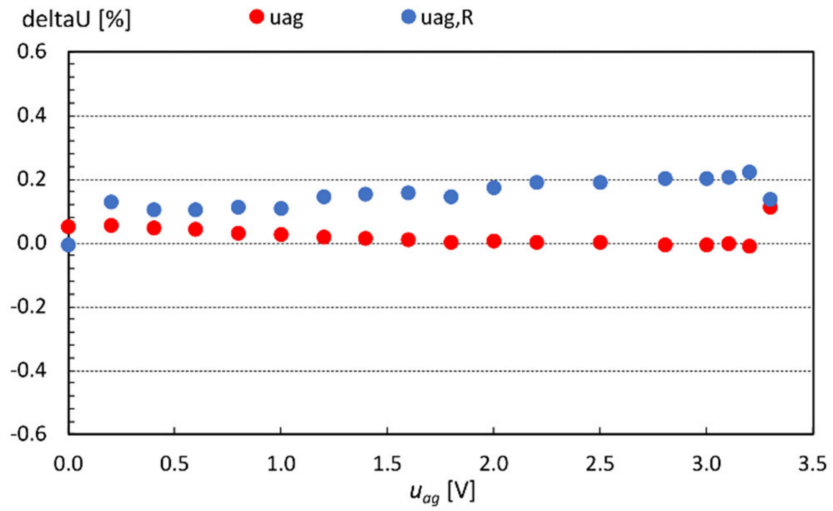

(a)

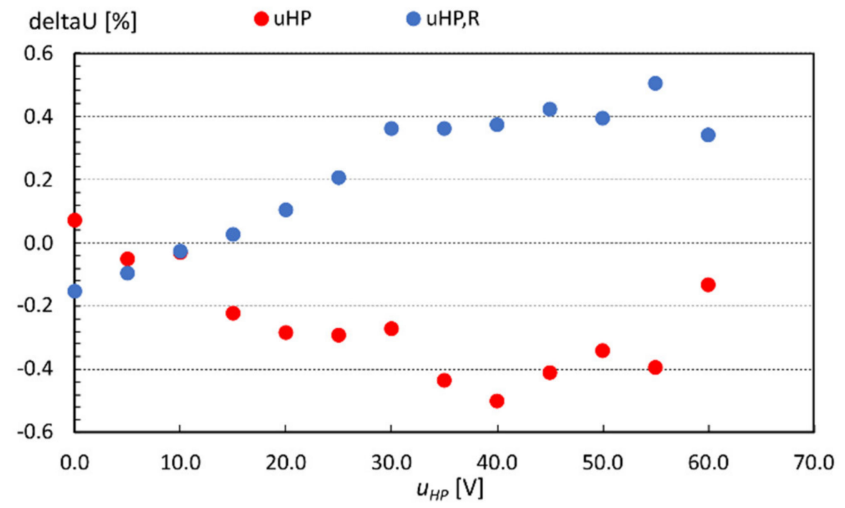

(b)

Figure 16. Voltage error for original and reversed polarity of measured voltage on the nominal range: (a) for $u_{a g} ;(\mathbf{b})$ for $u_{H P}$. 


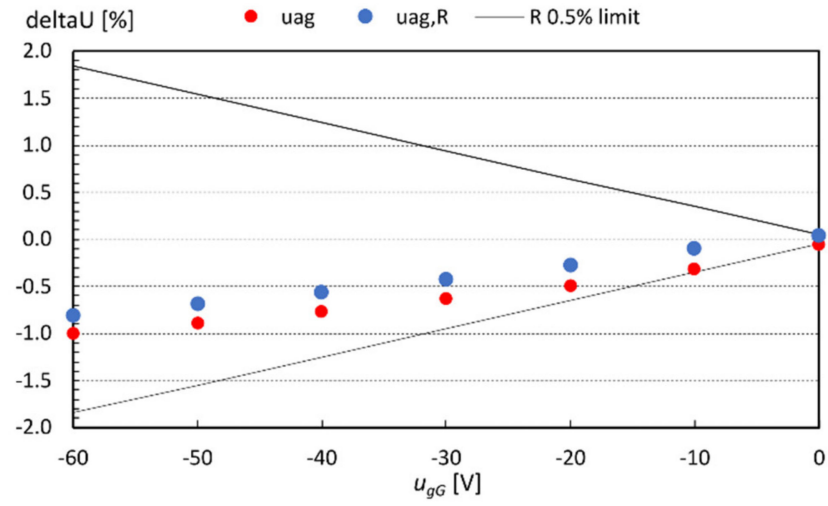

(a)

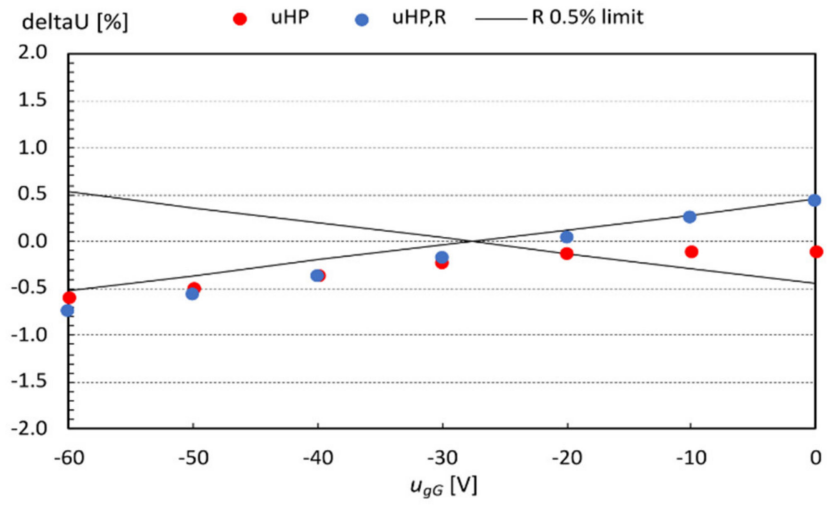

(b)

Figure 17. Voltage error vs. $u_{g G}$ for original and reversed polarity of measured voltage: (a) for $u_{a g}=3.3 \mathrm{~V} ;(\mathbf{b})$ for $u_{H P}=60 \mathrm{~V}$.

For practical reasons, required voltage references were obtained using a resistor divider and an $\mathrm{OP}$ amp voltage follower in all presented cases. However, as discussed before (results in Figures 13 and 14), connecting the measured voltage to the signal conditioning circuit with the opposite polarity, the reference voltage selection can be simplified, since in all cases the reference voltage should be set to a value of the positive supply rail $(+3.3 \mathrm{~V})$. In this case, the output voltage of the signal conditioning circuit is reversed (i.e., for $u_{a g}=3.3 \mathrm{~V}$, the OP amp output is at $3.128 \mathrm{~V}$ and for $u_{a g}=0 \mathrm{~V}$ the OP amp output is at $3.3 \mathrm{~V}$ ), so it needs to be properly recalculated in the microcontroller where all measured voltages are recalculated anyway. As seen from results, the reversed polarity does not hinder the circuits performance, since it provides comparable results, yet with a voltage reference that is easier available on the market.

To validate the proposed procedure for circuit parameter calculation, another voltage $\left(u_{c p s}\right)$ from the auxiliary circuit with a maximum value of $18 \mathrm{~V}$ was also measured. For this, we used a gain of $G^{*}=0.0422$ and $u_{R E F}^{*}=2.532 \mathrm{~V}$, again resulting in a relatively low voltage deviation from the calculated value for the input $u_{c p s}$ and $u_{g G}$ change, as seen from Figure 18a,b, respectively.

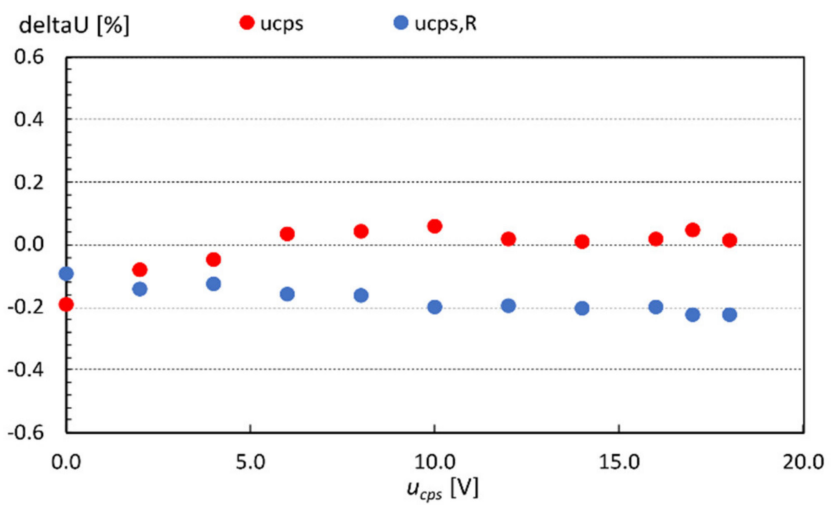

(a)

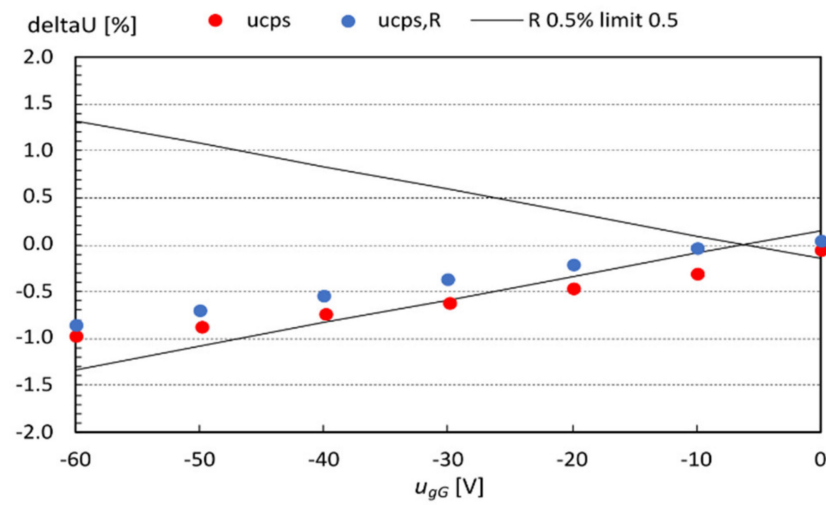

(b)

Figure 18. Voltage error for $u_{c p s}$ measurement: (a) for the nominal range from $0 \mathrm{~V}$ to $u_{c p s}=18.0 \mathrm{~V}$; (b) for $u_{c p s}=18.0 \mathrm{~V}$ vs. $u_{g G}$.

\section{Conclusions}

In this paper, two signal conditioning circuits for a differential voltage measurement based on single-supplied RRIO OP amps were analysed. With the proposed circuit's parameter calculation procedure, a voltage measurement with both differential circuits is possible even if the measured voltage includes a CMV, varying in magnitude and polarity. 
After simulation results for both circuits were compared, a decision for the circuit that performs the signal conditioning task the best and is at the same time cost-effective and easy to implement, is not that straight forward. On one side, a single-stage circuit (Figure 3) could be superior compared to the two-stage circuit (Figure 5) on account of a lower number of components. Also, with a reversed terminal connection, selecting the reference voltage component is significantly simplified, since its value equals the positive supply rail $\left(U_{S_{+}}\right)$. However, the output voltage does not occupy the whole available output range, and the OP amp inputs are exposed to a changing CMV that could result in output voltage distortion related to the input crossover issue.

On the other hand, selecting a two-stage circuit (Figure 5) offers a full-scale output range for the full-scale measured voltage range as long as the proposed procedure for parameter calculation is followed. With the two-stage topology, the CMV at OP amps inputs is constant irrespective of the measured voltage or imposed CMV value. However, for a practical implementation, a higher number of components-especially two reference voltages-could be a decisive factor against the use of the circuit. It is true though, that even with the reversed terminal connection, a certain simplification can be made, since the reference voltage of the first stage should be set to a negative supply rail (GND), yet still preserving the value of the reference voltage $u_{R E F 2}$.

As deduced from simulation results, a reversed connection of the measured voltage in both cases simplifies the voltage reference selection. Especially in the single-stage circuit experimentally verified, this could yield a significant cost decrease in mass production since all system voltages are measured with signal conditioning circuits having the same reference voltage and same electrical scheme. The only difference lies therefore in resistor values, defining appropriate gains for individual measured voltages.

According to numerical data presented, the gain of the signal conditioning circuit is set significantly below 0.1 , which restricts the usage of dedicated ICs, such as instrumentation amplifiers, since they are in general optimized for voltage gains higher than 1 . On the other hand, the use of difference amplifier ICs with built-in precision resistors offers only a limited gain adjustment. That is why a custom-built difference amplifier has a vital role in cost-sensitive applications regardless of the inherently lower common-mode rejection ratio (CMRR). Consequently, a practical implementation of the signal conditioning circuit in the high-power device relies not only on a selection of suitable circuits and their components but also on a careful design of the printed circuit board.

Author Contributions: Conceptualization, M.P. and P.Z.; methodology, M.P.; validation, P.Z.; formal analysis, M.P.; investigation, M.P. and P.Z.; resources, P.Z.; writing—original draft preparation, M.P.; writing-review and editing, M.P. and P.Z.; visualization, M.P.; supervision, P.Z. Both authors have read and agreed to the published version of the manuscript.

Funding: This research was supported in part by Slovenian Research Agency; Javna agencija zaraziskovalno dejavnost Republike Slovenije, Bleiweisova cesta 30, 1000 Ljubljana, Slovenia, under Grant L2619 »Advanced electronic power supply for automotive catalytic converter«.

Conflicts of Interest: The authors declare no conflict of interest. The funders had no role in the design of the study; in the collection, analyses, or interpretation of data; in the writing of the manuscript, or in the decision to publish the results.

\section{References}

1. Hoff, C.; Sirch, O. Elektrik/Elektronik in Hybrid- und Elektrofahrzeugen und Elektrisches Energiemanagement VII, 1st ed.; Expert-Verlag: Renningen, Germany, 2016.

2. Cabizza, S.; Corradini, L.; Spiazzi, G.; Garbossa, G. Comparative Study of 48V-based Low-Power Automotive Architectures. In Proceedings of the 2020 IEEE 21st Workshop on Control and Modeling for Power Electronics (COMPEL), Virtual, Aalborg, Denmark, 9-12 November 2020; IEEE: New York, NY, USA, 2020; pp. 1-8. [CrossRef]

3. Lindenthaler, D.; Brasseur, G. Signal-Bandwidth Evaluation for Power Measurements in Electric Automotive Drives. IEEE Trans. Instr. Meas. 2015, 64, 1336-1343. [CrossRef]

4. Texas Instruments. Basics of Power Switches; Application Report. Available online: https://www.ti.com/lit/an/slva927a/slva927 a.pdf (accessed on 15 July 2021). 
5. Infineon. Smart High-Side Switches. Application Note. What a Designer Should Know. Available online: https: //www.infineon.com/dgdl/Infineon-Application+Note-PROFET+12V-What+the+designer+should+know-AN-v01_00 -EN.pdf?fileId=5546d46259b0420a0159d5c957260d9c (accessed on 5 August 2021).

6. Deutschmann, B.; Winkler, G.; Kastner, P. Impact of Electromagnetic Interference on the Functional Safety of Smart Power Devices for Automotive Applications. Elektrotechnik Informationstechnik. 2018, 135, 352-359. [CrossRef]

7. Carbajal-Retana, M.; Hernandez-Gonzalez, L.; Ramirez-Hernandez, J.; Avalos-Ochoa, J.G.; Guevara-Lopez, P.; Loboda, I.; SotresJara, L.A. Interleaved Buck Converter for Inductive Wireless Power Transfer in DC-DC Converters. Electronics 2020, 9, 949. [CrossRef]

8. Wu, Y.; Ke, Y.A. A Novel Bidirectional Isolated DC-DC Converter with High Voltage Gain and Wide Input Voltage. IEEE Trans. Power Electronics. 2021, 36, 7973-7985. [CrossRef]

9. Kumar, G.G.; Sai Krishna, M.V.; Kumaravel, S.; Babaei, E. Multi-Stage DC-DC Converter Using Active LC2D Network with Minimum Component. IEEE Trans. Circuits Syst. II Express Briefs 2021, 68, 943-947. [CrossRef]

10. Zelin, L.; Gaofeng, P. Design of real time system to measure the voltage signal in high voltage power supply. J. Phys. Conf. Ser. 2021, 1887. [CrossRef]

11. Niklaus, P.S.; Bortis, D.; Kolar, J.W. Next Generation Measurement Systems with High Common-Mode Rejection. In Proceedings of the 2018 IEEE 19th Workshop on Control and Modeling for Power Electronics (COMPEL), Padova, Italy, 25-28 June 2018; pp. 1-8. [CrossRef]

12. Reverter, F. The Art of Directly Interfacing Sensors to Microcontrollers. J. Low Power Electron. Appl. 2012, 2, 265-281. [CrossRef]

13. Cheng, Y.; Sun, Y.; Li, X.; Dan, H.; Lin, J.; Su, M. Active Common-Mode Voltage-Based Open-Switch Fault Diagnosis of Inverters in IM-Drive Systems. IEEE Trans. Ind. Electron. 2021, 68, 103-115. [CrossRef]

14. Dimitrov, B.; Collier, G.; Cruden, A. Design and Experimental Verification of Voltage Measurement Circuits Based on Linear Optocouplers with Galvanic Isolation for Battery Management Systems. World Electr. Veh. J. 2019, 10, 59. [CrossRef]

15. ON Semiconductor. NCV5230. Available online: https://www.onsemi.com/pub/Collateral/NE5230-D.pdf (accessed on 15 July 2021).

16. Texas Instruments. TLV9001. Available online: https://www.ti.com/lit/ds/symlink/tlv9001.pdf (accessed on 15 July 2021).

17. Hornero, G.; Casas, O.; Pallàs Areny, R. Common mode response effects in differential measurements. AEU Int. J. Electron. Commun. 2021, 128. [CrossRef]

18. Zhou, J.; Liu, J. On the measurement of common-mode rejection ratio. IEEE Trans. Circuits Syst. II Express Briefs 2005, 52, 49-53. [CrossRef]

19. Analog Devices. AD628. Available online: https://www.analog.com/media/en/technical-documentation/data-sheets/AD628 .pdf (accessed on 15 July 2021).

20. Saponara, S.; Ciarpi, G. Electrical and Electromagnetic Measurements of an Inductorless DC/DC Converter. In Proceedings of the I2MTC2017 Conference, Pisa, Italy, 22-25 May 2017. [CrossRef]

21. Saponara, S.; Ciarpi, G. Electrical, Electromagnetic, and Thermal Measurements of 2-D and 3-D Integrated DC/DC Converters. IEEE Trans. Instr. Meas. 2018, 67, 1078-1090. [CrossRef]

22. Han, D.; Morris, C.T.; Lee, W.; Sarlioglou, B. A Case Study on Common Mode Electromagnetic Interference Characteristics of GaN HEMT and Si MOSFET Power Converters for EV/HEVs. IEEE Trans. Transp. Electrif. 2017, 3, 168-179. [CrossRef]

23. Huang, K.; Liu, Z.; Zhu, F.; Zheng, Z.; Cheng, Y. Evaluation Scheme for EMI of Train Body Voltage Fluctuation on the BCU Speed Sensor Measurement. IEEE Trans. Instr. Meas. 2017, 66, 1046-1057. [CrossRef]

24. Counts, L.; Kitchin, C. A Designer's Guide to Instrumentation Amplifiers, 3rd ed.; Analog Devices: Wilmington, NC, USA, 2006; pp. 154-196.

25. Azhari, S.J.; Fazlalipoor, H. CMRR in Voltage-Op-Amp-Based Current-Mode Instrumentation Amplifiers (CMIA). IEEE Trans. Instr. Meas. 2008, 58, 563-569. [CrossRef]

26. Texas Instruments. INA117. Available online: https://www.ti.com/lit/ds/symlink/ina117.pdf (accessed on 15 July 2021).

27. Analog Devices. Instrumentation Amplifier Common-Mode Range: The Diamond Plot. Available online: https://www.analog. $\mathrm{com} / \mathrm{media} / \mathrm{en} /$ technical-documentation/application-notes/AN-1401.pdf (accessed on 15 July 2021).

28. Texas Instruments. INA240 High- and Low-Side, Bidirectional, Zero-Drift, Current-Sense Amplifier with Enhanced PWM Rejection. Available online: https:/ / www.ti.com/product/INA240 (accessed on 7 August 2021).

29. Leon, E.; Barthel, R.; Alani, T. Zero-Crossover Amplifiers: Features and Benefits. Texas Instruments. Available online: https: //www.ti.com/lit/an/sboa181a/sboa181a.pdf (accessed on 15 July 2021).

30. Mancini, R. Op Amps for Everyone; Texas Instruments: Dallas, TX, USA, 2002; p. 418.

31. Texas Instruments. Voltage Reference Selection Basics. Available online: https://www.ti.com/lit/wp/slpy003a/slpy003a.pdf (accessed on 15 July 2021).

32. Maxim. Understanding Voltage-Reference Temperature Drift. Application Note. Available online: https://www. maximintegrated.com/en/design/technical-documents/app-notes/4/4419 (accessed on 15 July 2021).

33. Texas Instruments. LM4140 High Precision Low Noise Low Dropout Voltage Reference. Available online: https://www.ti.com/ lit/ds/symlink/lm4140.pdf (accessed on 15 July 2021).

34. Analog Devices. Precision Series Sub-Band Gap Voltage Reference. Available online: https://www.analog.com/media/en/ technical-documentation/data-sheets / ADR130.pdf (accessed on 15 July 2021). 
35. Ueno, K.; Hirose, T.; Asai, T.; Amemiya, Y. A 300 nW, 15 ppm $/{ }^{\circ} \mathrm{C}, 20$ ppm/V CMOS Voltage Reference Circuit Consisting of Subthreshold MOSFETs. IEEE J. Solid-State Circuits 2009, 44, 2047-2054. [CrossRef]

36. Magnelli, L.; Crupi, F.; Corsonello, P.; Pace, C.; Iannaccone, G. A 2.6 nW, 0.45 V Temperature-Compensated Subthreshold CMOS Voltage Reference. IEEE J. Solid-State Circuits 2011, 46, 465-474. [CrossRef]

37. Liu, Y.; Zhan, C.; Wang, L.; Tang, J.; Wang, G. A 0.4-V Wide Temperature Range All-MOSFET Subthreshold Voltage Reference with $0.027 \%$ /V Line Sensitivity. IEEE Trans. Circuits Syst. II Express Briefs 2018, 65, 969-973. [CrossRef]

38. Lee, I.; Sylvester, D.; Blaauw, D. A subthreshold voltage reference with scalable output voltage for low power IoT systems. IEEE J. Solid-State Circuits 2017, 52, 1443-1449. [CrossRef]

39. Richelli, A. Low-Voltage Integrated Circuits Design and Application. Electronics 2021, 10, 89. [CrossRef] 